\title{
Effects of Environmental Controls on the Growth of Wasabi (Eutrema japonica (Miq.) Koidz.) in a Nutrient Solution Cultivation System
}

\author{
Shoji OGUni***, Kazumasa KaKibuchi** and Yoshihiro Katayama* \\ * Graduate School of Bio-Applications and Systems Engineering, Tokyo University of \\ Agriculture and Technology, 3-5-8 Naka-cho, Koganei, Tokyo 184-8588, Japan \\ ** Shikoku Research Institute Inc. 2109-8 Yashimanishi-machi, Takamatsu, Kagawa 761-0192, Japan
}

(Received January 31, 2005)

\begin{abstract}
The effects of controlling minimum nocturnal ambient air temperature, day length and culture medium temperature on growth and yield were studied for the purpose of developing a yearround cultivation system for wasabi (Eutrema japonica (Miq.) Koidz.). When the minimum night temperature was $5^{\circ} \mathrm{C}$ in winter, the growth of wasabi leaf was slow but recovered when the temperature rose to $8^{\circ} \mathrm{C}$. Extension of day length by supplemental lighting was found to enhance growth recovery. Wasabi was planted at different times of the year to compare the effects of seasonal variation on stem growth. The mean daily growth medium temperature was maintained at $13.5-28.1^{\circ} \mathrm{C}$ throughout the year. These results revealed little difference in growth and stem pungency due to the season of planting, and stems grew to about $60 \mathrm{~g}$ within two years of cultivation. Year-round, stable nutrient solution cultivation of wasabi under environmental control may be an economically feasible alternative to conventional, labor-intensive cultivation systems.
\end{abstract}

Keywords : allyl isothiocyanate, growth medium temperature, lighting, rockwool

\section{INTRODUCTION}

Wasabi is a spice crop of the family Brassicaceae, and its grated stem is an essential ingredient for the preparation of sashimi (raw fish) and sushi (raw fish on steamed rice) (Adachi, 1987; Chadwick et al., 1993). Its young leaves are used for food pickling and culinary presentation. Wasabi is a highly profitable crop, suitable for hilly and mountainous regions (Yokogi and Ueno, 1990). So-called sawa (swamp) wasabi, which is cultivated in terraced fields with running stream water in chilly, elevated regions, is particularly high in quality and commands a high price. However, because many regions with an abundant supply of stream water are located in steep mountainous areas where farming populations are aging, there is a demand for intensive and laborsaving methods for wasabi cultivation that can be practiced near residential areas of Japan (Tanifuji, 1997). There is also a concern that wasabi may not grow and develop well in chilly elevated regions of mountains where air temperatures are low in winter and mountain shade severely limits day length. To solve these problems, we have investigated an automated cultivation system with environmental and nutrient control.

There have been a number of reports on wasabi cultivation under controlled environmental

\footnotetext{
Corresponding author: Shoji Oguni, fax : +81-87-844-9230,
} e-mail : soguni@ssken.co.jp 


\section{S. OGUNI ET AL.}

conditions. Ina (1998) reported the effect of water temperature on the growth and development of wasabi in sand-gravel hydroponics simulating flooded field cultivation in a plastic house with the maximum air temperature at $24.7^{\circ} \mathrm{C}$, the minimum air temperature at $4.6^{\circ} \mathrm{C}$, and an average air temperature of $14.4^{\circ} \mathrm{C}$. Hassan et al. $(1991,2001)$ performed tests of sand-gravel hydroponics and nutrient film cultivation in a shaded environment and reported the effect of nutrient solution temperature on growth and development. Miyazaki et al. (1991) reported on the year-round cultivation of wasabi by running solution and mist cultures with localized air conditioning. However, all of these reports are limited to the developmental stage and there has been no published report of wasabi cultivated commercially under controlled environmental conditions, likely due to the lack of an efficient and cost-effective method for controlling air, water and especially growth medium temperature which is considered to be particularly important for wasabi cultivation.

The authors have developed a low cost growth medium temperature control system by storing heat through air conditioning with a heat pump at night and application to day-neutral strawberry cultivation in chilly elevated regions (Kakibuchi et al., 1998). The strawberry cultivation system was applied to wasabi cultivation and the effects of controlling air temperature, growth medium temperature, day length, and the timing of planting on the yield and quality were studied as a means of addressing the economic and cultural issues associated with the production of wasabi.

\section{MATERIALS AND METHODS}

1. Test facilities

1) Greenhouse facilities

(1) Main structure of greenhouse

An iron-framed, round-roofed plastic greenhouse with $6 \mathrm{~m}$ frontage, $30 \mathrm{~m}$ depth, $2.3 \mathrm{~m}$ eaves height, and $3.8 \mathrm{~m}$ ridge height was built in Kazurahara-Nanotani (elevation, about $670 \mathrm{~m}$ ), Ino Town, Agawa County, Kochi Prefecture. The side windows were covered with $0.8 \mathrm{~mm}$ mesh insect nets to prevent the entry of insect pests (Fig. 1).

\section{(2) Heat and ventilation}

A hot-air heater with the capacity of $32,000 \mathrm{kcal} \mathrm{hr}^{-1}(37.2 \mathrm{~kW})$ was used. A ventilation fan with the capacity of $350 \mathrm{~m}^{3} \mathrm{~min}^{-1}$ (FGS1041, Fulta Electric Machinery Co., Ltd., Nagoya, Japan) and an automatic controlling apparatus ("Sotosaido W", Seiwa Co., Ltd., Tokyo, Japan) for the side

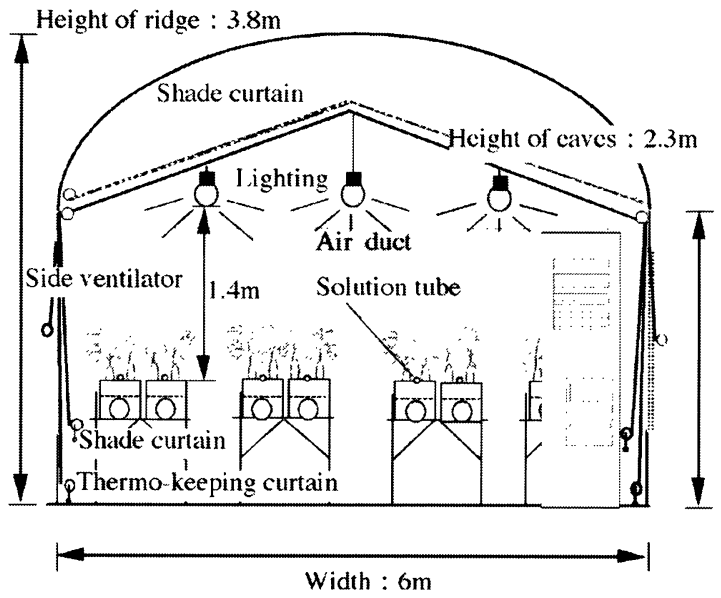

Fig. 1 Cross section of greenhouse. 


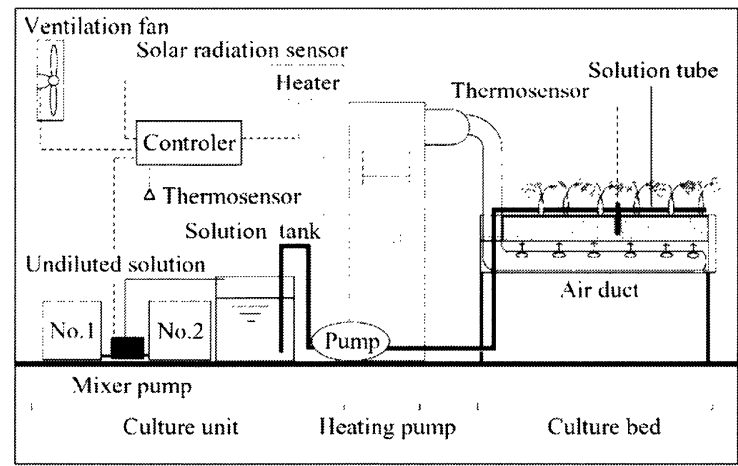

Fig. 2 Construction of system.

windows were installed (Figs. 1, 2).

\section{(3) Insulation curtain}

Insulation during heating was improved with manually wound insulation lining for the ceiling and sides. Insulation curtains were also provided for the ends of the eaves (Fig. 1).

\section{(4) Shading curtain}

Shading curtains ("DioNet" 1210 SG, Dio Chemicls, Ltd., Tokyo, Japan) were erected in the greenhouse for $70 \%$ shading from April 8 to October 30, 2000. Curtains ("DioNet" 819SG) were erected for 55\% shading from April 12 to September 20, 2001. Manually wound curtains also covered the sides of the greenhouse for shading (Fig. 1).

\section{(5) Supplemental illumination}

Fixtures containing 75W incandescent lamps ("Minori", Matsushita Electric Industrial Co., Ltd., Osaka, Japan) were placed $140 \mathrm{~cm}$ from the surface of cultivation beds and above the passage in the greenhouse to keep the photosynthetic photon flux density (PPFD) at $0.5-2.0 \mu \mathrm{mol} \mathrm{m}^{-2} \mathrm{sec}^{-1}$ on lamina surfaces (Fig. 1).

\section{2) Equipment for growth medium temperature control}

A bottom plate with holes was placed at a depth of $12 \mathrm{~cm}$ in a cultivation bed $(33 \mathrm{~cm}$ wide, $35 \mathrm{~cm}$ deep, $3 \mathrm{~cm}$ thick) made of styrofoam as shown in Fig. 1. Nonwoven fabric ("Lovesheet" \#20307BKD, Unitika Ltd., Osaka, Japan) was spread over the bottom plate, and cultivation beds were filled with granular rockwool (Nichias Corporation, Tokyo, Japan) as the growth medium. The upper surface of the medium was covered with white "Tyvek sheets" (E. I. du Pont de Nemours \& Company, Inc., Delaware, USA).

The cultivation beds were elevated so that the upper surface was $90 \mathrm{~cm}$ from ground level (Figs. 1, 2). Rows were formed with two beds, and four rows (three $26 \mathrm{~m}$ rows, one $25 \mathrm{~m}$ row) were set up in the greenhouse with a total cultivation bed length of $206 \mathrm{~m}$.

Air temperature was controlled with an air conditioner exclusively for the growth medium (PSS-J140GA, Mitsubishi Electric Building Techno-Service Co., Ltd., Tokyo, Japan) with a cooling capacity of $12,500 \mathrm{kcal} \mathrm{hr}^{-1}(14.0 \mathrm{~kW})$ and a heating capacity of $14,000 \mathrm{kcal} \mathrm{hr}^{-1}(16.0 \mathrm{~kW})$. Temperature-controlled air was introduced from below the growth medium through $150 \mathrm{~mm}$ dia. plastic (with $25 \mathrm{~mm}$ dia. forced air holes at $60 \mathrm{~cm}$ intervals) at constant pressure with a pressurizing fan with a capacity of $35 \mathrm{~m}^{3} \mathrm{~min}^{-1}$ from 22:00 until 08:00 to control the growth medium temperature (Fig. 2). This system allowed heat generated from low-cost night-time electric power to be stored in the growth medium. However, it was possible to use additional energy when day-time temperatures fluctuated outside the prescribed range. 


\section{3) Solution supply equipment}

Nutrient solution supply was controlled with a timer and in relation to solar radiation. Drip irrigation tubes ("Streamline" 80-01, Netafim Ltd., Tel Aviv, Israel) with drip holes at $10 \mathrm{~cm}$ intervals were installed along the centers of the cultivation beds. The nutrient solution was automatically diluted to a prescribed electrical conductivity (EC) by pumping stock nutrient solution into water stored in a 500 liter solution supply tank (Fig. 2).

\section{Cultivation method}

1) Planting

Mericlone plantlets of 'Mazuma Select No.1' (Miyoshi Co., Ltd., Tokyo, Japan) were planted in the styrofoam, off-set in rows with $12 \mathrm{~cm}$ between hills and $20 \mathrm{~cm}$ between rows on December 15,1999 . To assess the possibility of year-round, continuous harvest of wasabi, 580 plantlets were planted on April 6, July 19, October 24, and December 21, 2000 and the effect of planting dates on the rate of stem growth was evaluated.

\section{2) Air temperature control}

The greenhouse was ventilated by opening and closing side windows and with the ventilation fan to a maximum temperature of $35^{\circ} \mathrm{C}$ in summer and $25^{\circ} \mathrm{C}$ in winter. Nocturnal air was heated to a minimum temperature of $8^{\circ} \mathrm{C}$ from December 15,1999 , to April 30,2000 , and $5^{\circ} \mathrm{C}$ from November 18, 2000, to January 24, 2001, to reduce cultivation costs and evaluate the effects of minimum night-time temperatures on leaf growth. However, because growth and development in the initial phase of the experiment was observed to decrease, air was heated to $8^{\circ} \mathrm{C}$ or higher from January 25 to April 27, 2001, and from October 13, 2001, to the completion of the study in the following year.

\section{3) Growth medium temperature control}

The growth medium was heated to the target temperature of $20^{\circ} \mathrm{C}$ at night in winter and cooled to the target of $13^{\circ} \mathrm{C}$ at night in summer. The air conditioner used exclusively for growth medium temperature control was operated additionally when day-time temperatures declined to $13^{\circ} \mathrm{C}$ or lower in winter or exceeded $23^{\circ} \mathrm{C}$ in summer to keep day-time temperatures in excess of $13^{\circ} \mathrm{C}$ in winter and $23^{\circ} \mathrm{C}$ or lower in summer.

The heat pump was switched from heating to cooling on April 8, 2000 and May 12, 2001, and from cooling to heating on October 31, 2000 and October 25, 2001.

4) Day length control

Day-length extension illumination was kept on from 16:30 to 21:00 by timer control during the period from October 25, 2001 to February 18, 2002 to test the effects of long day length on growth and development. An un-illuminated test plot was set up on December 15, 1999 as a control.

\section{5) Solution management}

A $30 \mathrm{ml}$ supply per plant of Otsuka A nutrient solution ("Otsuka House" No.1, 2 and 5, Otsuka Chemicals Co., Ltd., Osaka, Japan) with an $\mathrm{EC}=1.2 \pm 0.2 \mathrm{dS} \mathrm{m}^{-1}$ was supplied at 09:00 by timer while the medium was cooled. Some hours after the timer-controlled supply, an additional $30 \mathrm{ml}$ aliquot was supplied when accumulated solar radiation for 10 min reached $10,000 \mathrm{~mol} \mathrm{~m}^{-2} \mathrm{se}$ $\mathrm{c}^{-1}$. The amount supplied was increased to $40 \mathrm{ml}$ per plant and the timer-controlled supply was made twice, at 09:00 and 13:00, to prevent the growth medium from drying while it was heated.

6) Defoliation, pinching, and pest control

During the cultivation period, all axillary buds were removed from their bases, and 15-20 aged outer leaves per plant were pruned once a month. For pest control, the greenhouse was sprayed monthly with 50 liter of acidic water $(\mathrm{KCl}, \mathrm{pH}, 2.5)$ in a water-electrolyzing apparatus (AT-2500, Aiken Industrial Co., Ltd., Kochi, Japan). 


\section{Investigation methods \\ 1) Environment}

Ambient temperature, growth medium temperature, and solar radiation were measured. Air temperatures inside and outside the greenhouse were measured at $1.5 \mathrm{~m}$ from the ground surface with a T-type thermocouple, which was also used to measure the growth medium temperature at a depth of $9 \mathrm{~cm}$ at the centers of the cultivation beds.

A solar radiation sensor (ML-020V, Eko Instruments Co., Ltd., Tokyo, Japan) was used to measure solar radiation inside and outside the greenhouse $2.0 \mathrm{~m}$ above the ground. The data obtained were recorded in a data logger (LE 2000, Chino Corporation, Tokyo, Japan) every $10 \mathrm{~min}$.

2) Growth and development

The largest leaves of 10 plants in each test plot were measured for petiole length, and lamina length and width as indicators of growth and development. In addition, 10 plants each were harvested, petioles were cut at $3 \mathrm{~cm}$ from their bases, and the stems were weighed after removing all fibrous roots.

\section{3) Allyl isothiocyanate (AITC) content}

Three wasabi plants from the December, 1999 planting were harvested in December, 2001; the whole stems were macerated after removing petioles and fibrous roots, and analyzed for AITC content by gas chromatography. Concurrently, stems of three plants of commercially available wasabi produced in Shizuoka Prefecture were analyzed.

Quantitative analysis was performed by the method described by Furuta et al. (1988). Extracts were made by incubating a $0.5 \mathrm{~g}$ sample in $3 \mathrm{ml}$ of water at $37^{\circ} \mathrm{C}$. After $30 \mathrm{~min}, 6 \mathrm{ml}$ of ethanol containing cyclopentanol as an internal standard was added and shaken for $10 \mathrm{~min}$. The eluant was filtered through a membrane filter immediately before injection into a 5\% PEG-20M/Chromosorb WAW DMCS (100-120 mesh, $\phi 3 \mathrm{~mm} \times 2 \mathrm{~m})$ gas chromatograph column at $100^{\circ} \mathrm{C}(\mathrm{GC}-14 \mathrm{~B}$, Shimadzu Co., Ltd., Kyoto, Japan). The inlet and the detector temperatures were maintained at $180^{\circ} \mathrm{C}$. Flame ionization was used for detection.
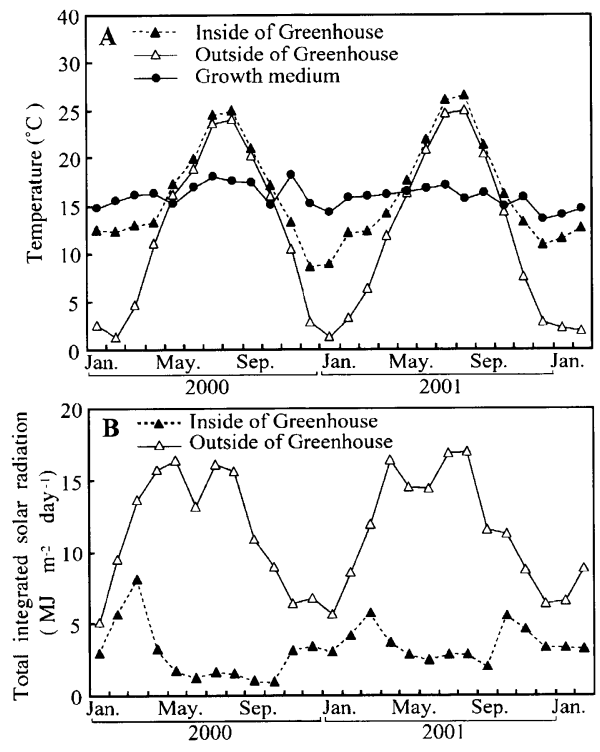

Fig. 3 Seasonal changes in monthly temperatures and solar radiation inside and outside greenhouse after transplanting. A: Temperatures B: Total integrated solar radiation 


\section{S. OGUNI ET AL.}
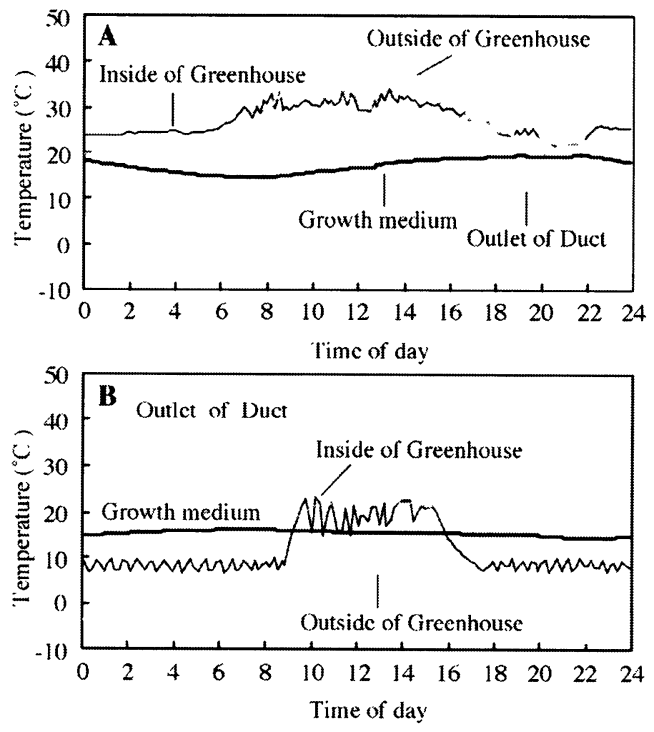

Fig. 4 Diurnal changes of air and growth medium temperatures on July 22 and February 3 in 2001. A: July 22 in 2001 (Cooling) B: February 3 in 2001 (Heating)

\section{RESULTS AND DISCUSSION}

\section{Environmental control}

1) Air temperature

The result of a year-round survey of temperature revealed that the average daily temperature could be maintained at around $25^{\circ} \mathrm{C}$ in summer by opening and closing the side windows in combination with use of the ventilation fan. Maximum temperatures remained at $35^{\circ} \mathrm{C}$ or lower (Fig. 3-A, Fig. 4-A).

The ventilation fan and heater were able to keep average daily temperatures at $12-15^{\circ} \mathrm{C}$, which is considered adequate for wasabi cultivation (Adachi, 1987), from November to April in the following year (Fig. 3-A, Fig. 4-B).

2) Growth medium temperature

The growth medium temperature was kept within the range of $13-23^{\circ} \mathrm{C}$, throughout the ex-

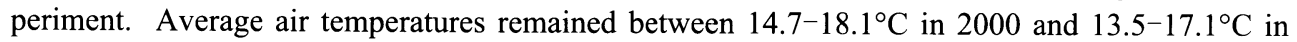
2001 (Fig. 3-A, Fig. 4).

Ina (1998) reported that when wasabi was cultured at nutrient solution temperatures of $8^{\circ} \mathrm{C}$, $13^{\circ} \mathrm{C}, 18^{\circ} \mathrm{C}$, and $23^{\circ} \mathrm{C}$, the best vegetative growth was obtained at $18^{\circ} \mathrm{C}$ for whole plant, at $13^{\circ} \mathrm{C}$ for main stem, and at $18^{-}-23^{\circ} \mathrm{C}$ for axillary bud development. Therefore, the growth medium temperature was within the optimum range for the growth and development of all but the stems of wasabi in this experiment.

\section{3) Amount of solar radiation}

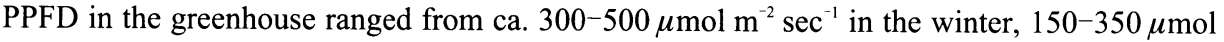
$\mathrm{m}^{-2} \mathrm{sec}^{-1}$ in the summer of 2000 when curtains were used for $70 \%$ shading, and 300-500 $\mu \mathrm{mol}$ $\mathrm{m}^{-2} \mathrm{sec}^{-1}$ in the summer of 2001, when curtains were used for $55 \%$ shading. Daily accumulated solar radiation remained at around $3.5 \mathrm{MJ} \mathrm{m}^{-2}$ day $^{-1}$ in the winter, $1.4 \mathrm{MJ} \mathrm{m}^{-2} \mathrm{day}^{-1}$ in the summer of 2000 , and $2.8 \mathrm{MJ} \mathrm{m}^{-2}$ day $^{-1}$ in the summer of 2001 (Fig. 3-B). Douglas and Follett (1992) reported that the light saturation point for wasabi was $500 \mu \mathrm{mol} \mathrm{m}^{-2} \mathrm{sec}^{-1}$. However, Ina (2000) 


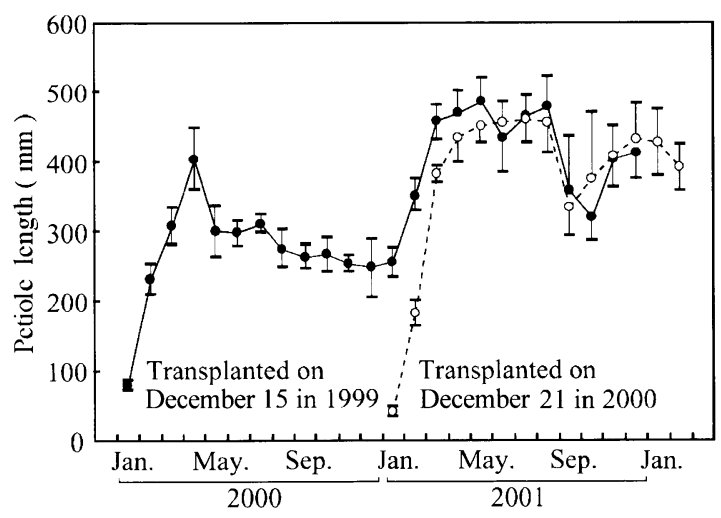

Fig. 5 Seasonal transition of petiole length. Vertical bars represent the standard deviation of the mean of 10 replications.

reported that adequate luminous intensity for the development of main stem of wasabi was around $20,000 \mathrm{~lx}$ (ca. $340 \mu \mathrm{mol} \mathrm{m}^{-2} \mathrm{sec}^{-1}$ ) and axillary buds tended to develop at 30,000 lx (ca. $500 \mu \mathrm{mol}$ $\mathrm{m}^{-2} \mathrm{sec}^{-1}$ ) or higher. Therefore, it was judged that adequate PPFD was available for the growth and development of stems during cultivation. However, the average daily accumulated solar radiation was less than $5.5 \mathrm{MJ} \mathrm{m}^{-2}$ day $^{-1}$, the level at which the growth and development of wasabi was reported to be most vigorous (Ina, 2002). The cause of these low levels in the present experiments was deemed to be insufficient accumulated solar radiation due to extremely short day length as the test site was located in a valley.

2. Growth and development

1) Seasonal variation of petiole length

Maruyama and Kawanishi (1965) reported that the growth of leaves and petioles is influenced by air temperature. Growth was good in spring and autumn but suppressed by high summer temperatures and extremely low temperatures in winter. Hence, petiole length was measured to evaluate the effect of air temperature on the growth and development of wasabi.

The petioles of wasabi planted in December, 1999 grew to about $400 \mathrm{~mm}$ in the spring of 2000 , became gradually shorter thereafter, and the newly developed petioles grew only to about $250 \mathrm{~mm}$ in the subsequent winter. Newly developed petioles grew to about $450 \mathrm{~mm}$ in March, 2001 and approximately $400 \mathrm{~mm}$ after August. This trend held true for wasabi planted in December 2000 (Fig. 5). In addition, plantlets planted in December were measured for leaf petiole length for two months. A statistical analysis was performed for data from the December 1999 planting, cultivated with the minimum nocturnal air temperature at $8^{\circ} \mathrm{C}$ and the December 2000 planting, cultivated with the minimum nocturnal air temperature at $5^{\circ} \mathrm{C}$. The results of the analysis revealed that leaf petioles of the December 1999 planting elongated significantly more both in January and February $(P<0.001)$.

Maruyama and Kawanishi (1965) reported that the foliage height of flood-cultured wasabi planted in October reached $513 \mathrm{~mm}$ in July of the following year, growth of newly developed petioles was gradually reduced to $204 \mathrm{~mm}$ in March, and increased to $663 \mathrm{~mm}$ in July. This seasonal variation was greater than what was observed in the present study, indicating that heating ambient air to a minimum nocturnal temperature of $8^{\circ} \mathrm{C}$ was responsible for reducing seasonal variation in petiole length by allowing greater winter petiole elongation.

2) Effects of minimum night temperature and day length on the growth and development of leaf

Adachi (1987) reported that the growth and development of wasabi was affected by air 

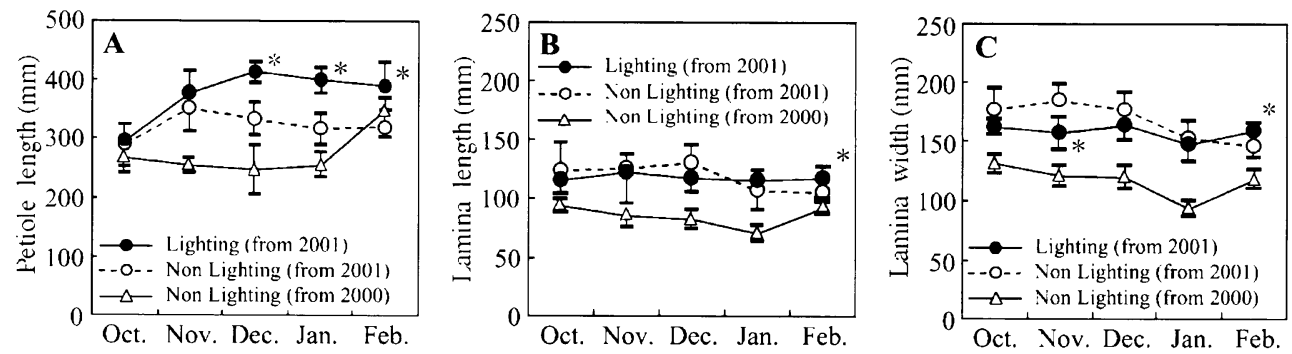

Fig. 6 Effects of day-length and minimum night-time temperatures on the growth of leaf. All plants were transplanted on December 15 in 1999. A: Petiole length B: Lamina length C: Lamina width Vertical bars represent the standard deviation of the mean of 10 replications.

*: Significant at $P=0.05$ between lighting and non lighting from October in 2001 .

temperature from the water surface to $60 \mathrm{~cm}$ above, that growth was retarded in winter when temperatures declined to $8^{\circ} \mathrm{C}$ or lower and stopped when temperatures fell below $5^{\circ} \mathrm{C}$. In addition, Miyazaki et al. (1991) and Sugiyama (2000) reported on the effects of day length on growth and development of wasabi, but did not perform evaluations over time. Hence, the effects of minimum nocturnal temperatures and day length on the growth and development of wasabi leaf were evaluated in this study, which is the first report of wasabi growth under controlled environmental conditions.

Figure 6 shows maximum petiole length, maximum lamina length and width during the periods from October, 2000 to February, 2001 when minimum nocturnal temperatures were kept at $5^{\circ} \mathrm{C}$, and from October, 2001 to February, 2002 when minimum night temperatures were kept at $8^{\circ} \mathrm{C}$. Day length was not controlled by supplemental lighting during either growth period.

Although no differences were found in petiole length in October, petioles were shortest when minimum night temperatures were kept at $5^{\circ} \mathrm{C}$ from November to January of the following year, and second shortest in the test plot with a minimum night temperature of $8^{\circ} \mathrm{C}$ and no supplemental lighting. However, although the growth of newly developed petioles gradually decreased when no lighting was provided, it remained nearly constant even after November, when artificial illumination was provided (Fig. 6-A).

The lengths and widths of lamina were affected by minimum night temperatures to a great extent and both increased at the minimum night temperature of $8^{\circ} \mathrm{C}$, compared with plants at $5^{\circ} \mathrm{C}$ (Fig. 6-B, C). Moreover, the effect of extended day length by supplemental illumination was manifested in plants with longer and wider laminae in February than plants with no supplemental lighting (Fig. 6-B, C).

Miyazaki et al. (1991) reported that day length extension to $14 \mathrm{~h}$ in winter was effective for decreasing the number of days before the harvest of leaf wasabi in heated nutrient solution cultivation with minimum night temperatures kept at $10^{\circ} \mathrm{C}$ in winter. Sugiyama (2000) stated that when day lengths of 8 and $16 \mathrm{~h}$ were compared in an artificial environment with air temperatures fixed at $15^{\circ} \mathrm{C}$ and $20^{\circ} \mathrm{C}$, foliage grew an additional $20^{-} 60 \mathrm{~mm}$ under longer day conditions. These reports suggest that extending the diurnal period by artificial lighting enhances growth and development through the expansion of laminal area and petiolar length as observed in short-day plants such as strawberry (Uematsu et al., 1979).

3) Effect of seasonal planting on stem growth and development

Ina (1996) reported on the effect of the timing of planting on the growth and development of wasabi in flooded culture, and stated that spring planting, when mean air temperatures increased for three months after planting, was suitable for stem growth and development. To our knowledge, however, there has been no report of tests under controlled environmental conditions. It is 

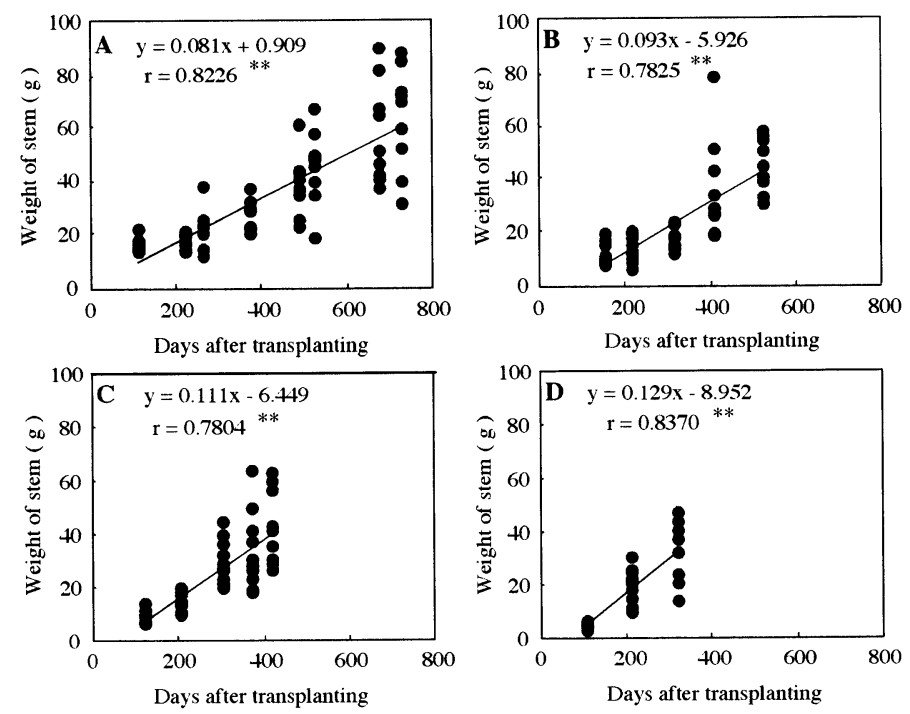

Fig. 7 Effect of seasonal planting on stem weight. A: Transplanted on December 15 in 1999 B: Transplanted on April 6 in 2000 C: Transplanted on July 19 in 2000 D: Transplanted on October 24 in 2000

**: Significant at $P=0.01$.

Table 1 Allyl isothiocyanate (AITC) in wasabi stem.

\begin{tabular}{lcc}
\hline & This work & Market \\
\hline Concentration $^{\mathrm{z}}$ & $0.33 \pm 0.012^{\mathrm{y}}$ & $0.27 \pm 0.067^{\mathrm{y}}$ \\
\hline${ }^{\mathrm{z}}$ Flesh weight $\%$. \\
${ }^{\mathrm{y}}$ Mean \pm Standard deviation $n=3$.
\end{tabular}

necessary to evaluate year-round planting and stable harvests to assure the efficient use of purposebuilt facilities.

Figure 7 shows the rate of stem weight increase for each time of planting. There was a high correlation between date of planting and stem weight. Linear regression gave a correlation coefficient ranging from $0.78-0.84$. Furthermore, the slopes of the regressions, which show the rate of growth and development, were all nearly 0.1 , suggesting that the difference in growth and development by planting time decreased and planting time had no influence on stem growth. Enhanced growth and development by heating and day length control in the winter is the likely cause.

Daily mean solar radiation generally remained lower than $5.5 \mathrm{MJ} \mathrm{m}^{-2} / \mathrm{day}^{-1}$ in the greenhouse during this cultivation test, which had been reported as suitable for wasabi by Ina (2002). The percentage of the optimum daily mean solar radiation measured in the greenhouse ranged from 53.0 to $103.0 \%$ without shading in the winter, about 16.6 to $59.1 \%$ with $70 \%$ shading, and 36.1 to $67.3 \%$ with $55 \%$ shading. However, stem weights reached about $60 \mathrm{~g}$ in two years. This result agrees with the growth results from flooded wasabi cultivation reported by Maruyama and Kawanishi (1965). Our results indicate that wasabi can be cultivated in this system at lower than $5.5 \mathrm{MJ} \mathrm{m}^{-2}$ day ${ }^{-1}$ daily accumulated solar radiation. From these results, it can be concluded that the season of planting made no difference in the growth and development of wasabi in this system, and that stable, yearround harvests were possible.

4. Quality evaluation

The quality of wasabi is evaluated by the content of AITC, which is the principle pungent component. AITC content has been quantified for tissue-cultured wasabi (Furuya et al., 1988), 


\section{S. OGUNI ET AL.}

wasabi harvested at different times (Hisatake, 1985) and in a comparison between sawa (swamp) wasabi and riku (upfield) wasabi (Sultana et al., 2003), but there has been no report of nutrient solution cultured wasabi stem AITC content.

The mean content of AITC in nutrient solution-cultured wasabi planted in December, 1999, accounted for about $0.32 \%$ of fresh weight. Wasabi grown in Shizuoka Prefecture, which was measured concurrently, produced about $0.27 \%$ (Table 1 ). The $0.32 \%$ content was higher than in varieties 'Daruma' (Sultana et al., 2003) and 'Mazuma' (Kojima, 1982; Arakawa et al., 2001). From these results, it can be concluded that drip irrigation culture using granular rockwool can produce sufficiently pungent stems without relying on a nutrient solution cultivation system, which approximates flooded culture.

We would like to thank Akira Ishikawa (Ino Town Office) and Seiichi Kato (Yonden Energy Service Co., Inc.) for supporting this research. We also would like to thank Keizou Hamauzu (Kochi Agricultural Extension Center) for the analysis of nutrient solutions. This work was performed with financial support from Shikoku Electric Power Co., Inc.

\section{REFERENCES}

Adachi, S. 1987. Wasabi cultivation. (Japanese text) Shujunsha, Tokyo, pp 199.

Arakawa, H., Ina, T., Matuura, H., Oba, S., Taneishi, M., Nakane, T. 2001. Content and distribution of pungent components in several cultivars and lines of wasabi (Wasabia japonica Matsum.). (Japanese text with English Summary) Bull. Shizuoka Agr. Exp. Stn. 46: 35-43.

Chadwick, C. I., Lumpkin, T. A., Elberson, L. R. 1993. The botany, uses and production of Wasabia japonica (Miq.) (Cruciferae) Matsum. Econ. Bot. 47: 113-135.

Douglas, J. A., Follett, J. M. 1992. Initial research on the production of water-grown wasabi in the Waikato. Proc. Agron. Soc. N.Z. 22: 57-60.

Furuya, T., Orihara, Y., Takagi, S., Yoshida, T. 1988. Differentiation and production of pungent components in Wasabia japonica tissue culture. (Japanese text with English Summary) Plant Tissue Culture Lett. 5: 8286.

Hassan, M., Iyanaga, K., Fujime, Y., Okuda, N. 1999. Sand-gravel hydroponic beds for wasabi. Thai J. Agr. Sci. 32: 253-261.

Hassan, M., Fujime, Y., Okuda, N., Matsui, T., Suzuki, H. 2001. Effects of solution temperature on the growth and development of wasabi grown in NFT. Tech. Bull. Fac. Agr. Kagawa Univ. 53: 13-18.

Hisatake, M. 1985. Differences of pungent components in "Wasabi", japanese horseradish between harvest times, varieties, cultivating places and amounts of fertilizer. (Japanese text) Rep. Ind. Tec. Cent. Kochi Pref. 16: 38-43.

Ina, T. 1996. Elucidation of air and water temperature conditions affecting the growth and development of wasabi (Wasabia japonica Matum.). (Japanese text) Summaries of Experiments and Research Results by the Shizuoka Agr. Exp. Stn. p14.

Ina, T. 1998. Influence of the temperature of water and air for the growth of Japanese horseradish. (Japanese text with English Summary) Bull. Shizuoka Agr. Exp. Stn. 43: 47-54.

Ina, T. 2000. Light conditions adequate for the cultivation of Japanese horseradish (Wasabia japonica Matum.). (Japanese text) Results of experiments and research related to agriculture, forestry, and fisheries by the Department of Agriculture, Forestry, and Fisheries, Shizuoka Pref. p 12-13.

Ina, T. 2002. Influence of the solar radiation on the growth of Japanese horseradish (Wasabia japonica Matsum.). (Japanese text with English Summary), Bull. Shizuoka Agr. Exp. Stn. 47: 25-33.

Kakibuchi, K., Yamamoto, K., Tanaka, M., Nakaoka, K. 1998. Cultivation of day-neutral strawberry, using the medium temperature control system. (Japanese text with English Summary) Shikoku Electric Power Co., /Shikoku Research Institute, Inc. Research Journal 70: 11-17.

Kojima, M. 1982. Science of wasabi [10]. (Japanese text) Agric. Hortic. 57: 107-112.

Maruyama, T., Kawanishi, K. 1965. Studies on thickening growth of wasabi. (Japanese text) Bull. Shizuoka Agr. Exp. Stn. 10: 131-145.

Miyazaki, M., Kameno, T., Okazaki, K., Kawasaki, K., Kotani, A., Itokawa, N., Amano, K., Higashio, H. 


\section{CULTIVATION OF WASABI}

1991. Development of small-scale hydraulic energy utilization for agriculture in mountainous regions technology for year round cultivation of the "Wasabi Leaf" - . (Japanese text with English Summary) Bull. Shikoku Agr. Exp. Cen. 54: 1-16.

Sugiyama, Y. 2000. Establishment of seed collection techniques for wasabi (Wasabia japonica Matum.) using fields and mother stocks prepared exclusively for seed collection. (Japanese text) Summaries of Experiments and Research Results by the Shizuoka Agr. Exp. Stn. 141-142.

Sultana, T., Porter, N.G., Savage, G.P., McNeil, D.L. 2003. Comparison of isothiocyanate yield from wasabi rhizome tissues grown in soil or water. J. Agr. Food Chem. 51: 3586-3591.

Tanifuji, I. 1997. Actual conditions of wasabi production in Okutama Town. (Japanese text) Rep. of Tec. Results by the Tokyo Metro. Agr. Exp. Stn. 1996: 23-26.

Uematsu, Y., Sada, M., Hagiwara, S. 1979. Studies on the regulation of growth of strawberry plants (Fragaria $\times$ ananassa Duch.) in lighting culture. I . Regulation of the growth of leaves and flower formation of strawberry plants with light treatments. (Japanese text with English Summary) Bull. Shizuoka Agr. Exp. Stn. 24: 54-60.

Yokogi, K., Ueno, R. 1990. Wasabi: A profitable side business in the mountains. (Japanese text) Rural Culture Association, Tokyo, pp 149. 